\title{
Xpert MTB/RIF for diagnosis of tuberculosis and drug-resistant tuberculosis: a cost and affordability analysis
}

\author{
Andrea Pantoja' ${ }^{1}$, Christopher Fitzpatrick ${ }^{1}$, Anna Vassall ${ }^{2,3}$, Karin Weyer $^{1}$ and \\ Katherine Floyd ${ }^{1}$
}

\section{Affiliations:}

${ }^{1}$ Global TB Programme, World Health Organization, Geneva, Switzerland.

${ }^{2}$ Dept of Global Health, and Amsterdam Institute of Global Health and Development, Academic Medical Center, Amsterdam, The Netherlands.

${ }^{3}$ Dept of Global Health and Development, London School of Hygiene and Tropical Medicine, London, UK.

\section{Correspondence:}

A. Pantoja, Stop TB Dept, World Health Organization, 20, Av Appia, Geneva, 1211, Switzerland. E-mail: andreagpantojadgmail.com

ABSTRACT Xpert MTB/RIF is a rapid test to diagnose tuberculosis (TB) and rifampicin-resistant TB. Cost and affordability will influence its uptake.

We assessed the cost, globally and in 36 high-burden countries, of two strategies for diagnosing TB and multidrug-resistant (MDR)-TB: Xpert with follow-on diagnostics, and conventional diagnostics. Costs were compared with funding available for TB care and control, and donor investments in HIV prevention and care.

Using Xpert to diagnose MDR-TB would cost US\$70-90 million per year globally and be lower cost than conventional diagnostics globally and in all high-burden countries. Diagnosing TB in HIV-positive people using Xpert would also cost US\$90-101 million per year and be lower cost than conventional diagnostics globally and in 33 out of 36 high-burden countries. Testing everyone with TB signs and symptoms would cost US\$434-468 million per year globally, much more than conventional diagnostics. However, in European countries, Brazil and South Africa, the cost would represent $<10 \%$ of TB funding.

Introducing Xpert to diagnose MDR-TB and to diagnose TB in HIV-positive people is warranted in many countries. Using it to test everyone with TB signs and symptoms is affordable in several middleincome countries, but financial viability in low-income countries requires large increases in TB funding and/or further price reductions.

@ERSpublications

Use of Xpert for diagnosis of MDR-TB and TB in HIV-positive people is financially viable and justified globally http://ow.ly/mzPsv

This article has supplementary material available from www.erj.ersjournals.com

Received: Sept 172012 | Accepted after revision: Dec 022012 | First published online: Dec 202012

Conflict of interest: None declared.

ERJ Open articles are open access and distributed under the terms of the Creative Commons Attribution NonCommercial Licence 3.0.

This article was modified in April 2016 to correct errors in the licence information. 


\section{Introduction}

Conventional diagnostic tests for tuberculosis (TB), including those for the detection of drug-resistant forms of TB and the diagnosis of TB in people living with HIV infection, have limitations that are major constraints to progress in global TB care and control [1-5]. Sputum smear microscopy, the most widely used test, has relatively low sensitivity in field conditions (typically in the range $50 \%-70 \%$ ), and cannot be used to identify paucibacillary $\mathrm{TB}$, extrapulmonary $\mathrm{TB}$ or drug resistance [6]. Diagnosis using culture methods, the current reference standard, requires laboratory infrastructure that is not widely available in most countries with a high burden of TB, and test results take up to 3 months to obtain.

In December 2010, the World Health Organization (WHO) endorsed a new rapid molecular test, called Xpert MTB/RIF (Cepheid, Sunnyvale, CA, USA). The test can simultaneously diagnose pulmonary TB and identify resistance to the most powerful firstline anti-TB drug, rifampicin. In five demonstration sites, the sensitivity of the test (compared with culture) for TB was $91 \%$ and specificity $99 \%$; for rifampicin resistance, sensitivity was $95 \%$ and specificity $98 \%$ [7]. The test takes $<2 \mathrm{~h}$ with minimal hands-on time [810]. In May 2011, WHO published policy guidance with a strong recommendation that Xpert MTB/RIF should be used as the initial diagnostic test in two groups of people: individuals suspected of multidrugresistant (MDR)-TB, and those living with HIV who are suspected of having TB [11]. MDR-TB is defined as resistance to at least rifampicin and isoniazid, the two most effective anti-TB drugs [12].

By the end of March 2012, around 61 countries had started to introduce Xpert MTB/RIF [13]; others are actively considering its introduction. Widespread implementation could help to achieve the diagnosis and treatment targets set out in the Global Plan to Stop TB 2011-2015 [13, 14]. In 2015, the target is to diagnose and treat almost 7 million people with drug-susceptible TB (up from 5.7 million in 2010) and 0.3 million people with MDR-TB (up from around 50000 in 2010). The funding required for treatment has been estimated at US\$ 1-2 billion per year for MDR-TB, and US\$ 4-5 billion per year for TB [14]. The plan was prepared before the endorsement of Xpert MTB/RIF by WHO, and hence did not consider the cost of using Xpert MTB/RIF to diagnosis TB and MDR-TB, or how these costs compare with those for conventional diagnostics.

Evidence and commentary on Xpert MTB/RIF are growing $[9,15,16]$. However, data on cost and costeffectiveness are currently limited to three countries. Use of Xpert MTB/RIF for the diagnosis of smearnegative pulmonary TB has been found to be cost-effective when compared with the alternative of sputum microscopy and radiographs in India, South Africa and Uganda [17]. The authors observed that it would be necessary to build on their study by evaluating the cost and affordability of Xpert MTB/RIF. A separate study in South Africa reported that Xpert MTB/RIF would increase the cost per case diagnosed [18], and a third study has suggested that the combination of smear microscopy followed by Xpert MTB/RIF (performed if smear-negative) has the highest accuracy and lowest cost compared with the use of each test in isolation [19].

In this article, we assess the cost and affordability of using Xpert MTB/RIF to diagnose TB and MDR-TB globally and in 36 high TB and MDR-TB burden countries, compared with the use of only conventional diagnostics.

\section{Methods \\ It should be stressed at the outset that our analysis focuses on comparing the costs of alternative approaches to diagnosis from the perspective of the health system and does not consider treatment costs of TB, MDR-TB and HIV, or costs from the perspective of patients. The reasons for not considering treatment costs are that treatments for TB and MDR-TB are the same following diagnosis by both Xpert MTB/RIF and conventional diagnostics, and that the costs of scaling up the treatment of TB and MDR-TB to reach global targets have already been assessed [14]. We acknowledge at the outset that because Xpert MTB/RIF makes diagnosis of drug-resistant TB much easier (when someone tests positive for TB, a result on rifampicin-resistance is available at the same time), it is likely to lead to a more rapid increase in people diagnosed with MDR-TB and associated treatment costs, compared with continued reliance on conventional diagnostics alone. The reason for not considering patient costs was that evidence on how these costs change when Xpert MTB/RIF is introduced is not yet available, although they could conceivably be lower given fewer patient visits.}

\section{Countries and target populations considered}

We considered the world as a whole, and 36 individual countries. The 36 countries appear in one or both of the lists of 22 high TB-burden countries that account for about $80 \%$ of TB cases globally [1], and 27 high MDR-TB burden countries that account for about $85 \%$ of the world's cases of MDR-TB [20]. 
TABLE 1 Methods used to estimate the number of tests required for target populations considered

\begin{tabular}{|c|c|c|}
\hline Three target populations & Description & Reference/First author [Ref.] \\
\hline \multicolumn{3}{|l|}{ All people with TB signs and symptoms } \\
\hline Shortened title used in figures & TB-SS & \\
\hline Number & $\begin{array}{l}\text { Assume } 10 \text { people with TB signs and symptoms per one } \\
\text { smear-positive TB case notified in } 2011\end{array}$ & 2011 Global TB Report [1] \\
\hline Conventional practice for diagnosis & Two smears and one radiograph for those smear-negative (S-X) & WHO guidelines [22] \\
\hline $\begin{array}{l}\text { Additional tests for South Africa, Russia, Estonia and } \\
\text { Kazakhstan }\end{array}$ & One culture test $(\mathrm{S}-\mathrm{X}-\mathrm{C})$ & \\
\hline Xpert MTB/RIF & One test per person & $\begin{array}{l}\text { Xpert MTB/RIF rapid implementation } \\
\text { guidance [21] }\end{array}$ \\
\hline $\begin{array}{l}\text { DST land culture) follow-on test when using Xpert } \\
\text { MTB/RIF (confirmatory test) }\end{array}$ & $\begin{array}{l}\text { One culture test followed by one DST for two firstline drugs } \\
\text { (rifampicin and isoniazid; solid or liquid) per patient with } \\
\text { rifampicin- resistant result with Xpert MTB/RIF }\end{array}$ & $\begin{array}{l}\text { Xpert MTB/RIF rapid implementation } \\
\text { guidance [21] }\end{array}$ \\
\hline $\begin{array}{l}\text { Proportion of Xpert tested patients with } \\
\text { rifampicin-resistant positive result }\end{array}$ & $\begin{array}{l}\text { Proportion of rifampicin resistance (where data are available); and } \\
\text { estimated proportion of new TB cases that have MDR-TB (if data } \\
\text { on rifampicin resistance are not available) }\end{array}$ & ZIGNOL [23] and 2011 Global TB Report [1] \\
\hline \multicolumn{3}{|l|}{$\begin{array}{l}\text { HIV-positive individuals (or HIV unknown in high HIV } \\
\text { settings) with TB signs and symptoms }\end{array}$} \\
\hline Shortened title used in figures & TB-SS, HIV positive & \\
\hline Number & $\begin{array}{l}\text { Proportion of tested TB patients HIV positive multiplied by all people } \\
\text { with TB signs and symptoms }\end{array}$ & 2011 Global TB Report [1] \\
\hline Conventional practice for diagnosis & Two smears, one radiograph and one culture (S-X-C) & WHO guidelines for TB/HIV [4] \\
\hline Xpert MTB/RIF & One test per suspect & $\begin{array}{l}\text { Xpert MTB/RIF rapid implementation } \\
\text { guidance [21] }\end{array}$ \\
\hline $\begin{array}{l}\text { DST land culture) follow-on test when using Xpert } \\
\text { MTB/RIF (confirmatory test) }\end{array}$ & $\begin{array}{l}\text { One culture test followed by one DST for two firstline drugs } \\
\text { (rifampicin and isoniazid; solid or liquid) per patient with } \\
\text { rifampicin-resistant result with Xpert MTB/RIF }\end{array}$ & $\begin{array}{l}\text { Xpert MTB/RIF rapid implementation } \\
\text { guidance [21] }\end{array}$ \\
\hline $\begin{array}{l}\text { Proportion of Xpert tested patients with } \\
\text { rifampicin-resistant positive result }\end{array}$ & $\begin{array}{l}\text { Proportion of rifampicin resistance (where data are available); and } \\
\text { estimated proportion of new TB cases that have MDR-TB (if data } \\
\text { on rifampicin resistance are not available) }\end{array}$ & ZIGNOL [23] and 2011 Global TB Report [1] \\
\hline \multicolumn{3}{|l|}{$\begin{array}{l}\text { Individuals at risk of having MDR-TB, diagnosed with } \\
\text { TB or with TB signs and symptoms }\end{array}$} \\
\hline Shortened title used in figures & MDR-TB, high-risk & \\
\hline Number & $20 \%$ of all new TB cases $+100 \%$ TB retreatment cases & 2011 Global TB Report [1] \\
\hline Conventional practice for diagnosis & $\begin{array}{l}\text { One culture test + one DST for two drugs (rifampicin and isoniazid; } \\
\text { solid or liquid media) }\end{array}$ & WHO guidelines for MDR-TB [12] \\
\hline Xpert MTB/RIF & One test per person & $\begin{array}{l}\text { Xpert MTB/RIF rapid implementation } \\
\text { guidance [21] }\end{array}$ \\
\hline $\begin{array}{l}\text { DST land culture) follow-on test when using Xpert } \\
\text { MTB/RIF (confirmatory test) }\end{array}$ & $\begin{array}{l}\text { One culture test followed by one DST for two firstline drugs } \\
\text { (rifampicin and isoniazid; solid or liquid) per patient with } \\
\text { rifampicin-resistant result with Xpert MTB/RIF }\end{array}$ & $\begin{array}{l}\text { Xpert MTB/RIF rapid implementation } \\
\text { guidance [21] }\end{array}$ \\
\hline $\begin{array}{l}\text { Proportion of Xpert tested patients with rifampicin } \\
\text { resistance result }\end{array}$ & $\begin{array}{l}\text { Proportion of rifampicin resistance (where data are available); and } \\
\text { estimated proportion of new TB cases that have MDR-TB (if data } \\
\text { on rifampicin resistance are not available) }\end{array}$ & ZIGNOL [23] and 2011 Global TB Report [1] \\
\hline
\end{tabular}

TB: tuberculosis; S: smear microscopy; X: radiograph; C: culture; DST: drug susceptibility testing; MDR-TB: multidrug-resistant tuberculosis.

In line with WHO policy guidance, we defined three target populations in which Xpert MTB/RIF could be considered [21]. The first group was all people presenting at health facilities with signs and symptoms consistent with TB. The size of this group was estimated using the numbers of TB cases reported by countries to WHO in 2011 [1], and the assumption (and widely used "rule of thumb") that for every reported case of smear-positive pulmonary $\mathrm{TB}$, there are $\sim 10$ people who would be tested for TB based on signs and symptoms. The second group was all people living with HIV (or whose HIV status is unknown in high HIV settings) presenting at health facilities with TB signs and symptoms. The size of this group was estimated according to the number of TB patients and the proportions of TB patients co-infected with HIV reported by countries to WHO in 2011 [1], and the same 10:1 ratio between people suspected of having TB and the number of people diagnosed with TB. The third group was all individuals considered at risk of having MDR-TB. The size of this group was estimated as $20 \%$ of new TB cases (those with defined risk factors for MDR-TB) and all previously treated TB cases, in accordance with targets set out in the global plan $[12,14]$. Further details are provided in tables 1 and 2.

\section{Alternative strategies}

For each population group, two alternative strategies for the diagnosis of TB and MDR-TB were considered. The first strategy was use of Xpert MTB/RIF, supplemented by follow-on tests using conventional diagnostics where appropriate. Follow-on tests for resistance to isoniazid (and to confirm rifampicin resistance in settings where such resistance is rare) using conventional methods are needed to confirm or rule-out MDR-TB for cases found to be rifampicin-resistant using Xpert MTB/RIF [21]. To estimate the number of TB patients who would need follow-on tests, we used the latest country data on levels of 
TABLE 2 Methods used to estimate the number of laboratories required, as per targets and indicators of the Global Plan to Stop TB 2006-2015

Assumptions

Description
One AFB microscopy laboratory per 100000 population; one culture laboratory per 5000000 population; one DST laboratory per 5000000 population

Baseline number of laboratories per country was obtained from the WHO's global TB database

This number was compared with the target number set out in the global plan

The difference is the number of laboratories that require new laboratory equipment for any of the three diagnostic methods

Capital investment for laboratories refers only to equipment, infrastructure is not included

rifampicin resistance in new and previously treated cases [23]. The second strategy was the use of conventional diagnostic algorithms according to WHO guidelines, which involve smear microscopy, culture examinations, drug susceptibility tests on solid or liquid media, and radiographs $[4,12,22]$. The types and quantities of tests required in each diagnostic strategy, and associated sources of evidence, are defined in detail in table 1.

We assumed that all population groups would receive the appropriate test(s), as recommended in the algorithm.

\section{Costs}

To estimate the annual resource requirements for the alternative strategies, the unit costs of all tests were estimated in US dollars using prices from the year 2011. All unit costs and respective sources of evidence are defined in detail in table $3[17,21,24-30]$. Seven points are worth highlighting. 1) The unit costs of culture and drug susceptibility testing (DST) were based on available literature [17, 25-28]. 2) The unit cost of a single Xpert MTB/RIF assay used in the baseline analysis (US\$ 9.98) was based on the outcome of price negotiations concluded in August 2012 [29]. 3) We assumed that one Xpert MTB/RIF cartridge per person tested is needed (a second test for TB using Xpert MTB/RIF for the same person is not recommended) [21]. 4) Costs for TB diagnosis using Xpert MTB/RIF include the annual costs of staff for performing the tests in the laboratory, annual calibration by the manufacturer and training [21].5) The additional laboratory equipment that would be needed for conventional testing was identified based on the targets set out in the Global Plan and the current capacity reported by countries (table 2).6) Capital costs (e.g. equipment) were annualised using a standard discount rate of 3\% [31] and an expected number of years of useful life of 5 years. 7) Costs were calculated for both solid and liquid media for culture and DST; the lower end of the range shown in the results represents costs when solid media are used and the upper end of the range represents costs when liquid media are used. 8) Staff costs were included in all of the different diagnostic strategies.

The total annual costs of each diagnostic strategy were calculated by multiplying unit costs by the quantities of tests required per year, for each country and target population.

We selected eight countries that illustrate results for countries in different geographic regions, countries that are both low and middle-income, and countries with varying burdens of HIV prevalence and MDR-TB. We then identified the countries that they represented, in terms of comparable relative patterns of costs when the alternative strategies were compared (for example, diagnostic costs for HIV-positive people with TB signs and symptoms were lower than costs associated with conventional diagnostics in the selected and represented countries). Results for all 36 countries are available in the online supplementary material. The eight countries, and the associated list of countries that they were considered to represent, are defined in table 4 .

\section{Affordability at country level}

We assessed affordability by comparing the costs of Xpert MTB/RIF relative to the funds that countries are already spending on health, in particular on TB care and control and on HIV prevention, treatment and care (the latter is of particular relevance to the costs of using Xpert MTB/RIF to diagnose TB among people living with HIV). We first compared costs with available funding for TB control in 2011 [1, 32]. Secondly, we compared costs with budgets reported to WHO by national TB control programmes. Thirdly, for African countries with a high burden of TB and HIV, we compared costs with 2011 country budgets allocated through the US President's Emergency Plan for AIDS Relief (PEPFAR) [33]. As the results for the second analysis were very similar to comparisons with available funding for TB care and control, only the results for the first and third analyses are reported in this paper. 


\section{TABLE 3 Cost assumptions and sources}

\section{Diagnostic tests and other annual costs \\ Smears}

Culture

DST for firstline drugs on solid media, per drug

DST for firstline drugs on liquid media, per drug

Digital radiograph

Xpert test, agreed price for second half of 2012

Annual calibration, annual technician salary, annual

training/technical assistance, annual cost per machine

\section{Laboratory equipment}

AFB microscopy equipment, per new laboratory

Culture in solid media, per new laboratory

(Culture and) DST lab in solid media, per new laboratory

MGIT for liquid culture and DST, per new laboratory

MGIT for liquid culture and DST for countries for which FIND

has negotiated prices, per new laboratory

GeneXpert machine, 4 modules

Shipment, Printer, UPS
1

$\begin{array}{cc}17.4(12.1-22.8) & 1 \\ 9.1(8.8-9.4) & 2 \\ 23.15(19.6-26.7) & 2 \\ 1.5 & 1 \\ 9.98 & 1 \\ 11800 & 1\end{array}$

$\begin{array}{cc}19624 & 1 \\ 177698 & 1 \\ 185681 & 1 \\ 79655 & 1 \\ 38950 & 1 \\ 17500 & 1 \\ 1700 & 1\end{array}$

TB Planning and Budgeting Tool [24] VASSAll [17], Tupasi [25], Mueller [26], SUÁREZ [27] and FLOYD [28]

Vassall [17], Tupasi [25], Mueller [26], SUÁREZ [27] and FLOYD [28] Vassall [17], Tupasi [25], Mueller [26], SUÁREZ [27] and FLOYD [28]

Recent experience in TB prevalence surveys UNITAID [29]

Xpert MTB/RIF rapid implementation guidance [21]

TB Planning and Budgeting Tool [24]

TB Planning and Budgeting Tool [24]

TB Planning and Budgeting Tool [24]

TB Planning and Budgeting Tool [24] FIND [30]

Xpert MTB/RIF rapid implementation guidance [21]

Xpert MTB/RIF rapid implementation guidance [21]

DST: drug susceptibility testing; AFB: acid-fast bacilli; MGIT: mycobacteria growth indicator tube; FIND: Foundation for Innovative New Diagnostics.

\#: 2011 prices; ": costs for infrastructure, annual maintenance, and quality assurance are not included.

\section{Sensitivity analysis}

Sensitivity analyses were undertaken for 1) the expected years of life of capital items (buildings and equipment) of 10 years instead of 5 years; and 2) the plausible range in the unit cost of culture, with a lower limit of US\$12.1 and an upper limit of US\$22.8 (table 3). There is also uncertainty about the size of the population requiring testing for TB and MDR-TB in both strategies, but any changes affect both strategies in the same way and therefore do not affect relative comparisons.

All analyses were performed using STATA SE 11 (StataCorp, College Station, TX, USA).

\section{Results}

Global number of tests and costs

Globally, $\sim 1.8$ million Xpert MTB/RIF assays per year would be needed to test patients at high risk of MDR-TB. For people living with HIV with TB signs and symptoms, $\sim 3.8$ million Xpert MTB/RIF tests per

TABLE 4 Countries selected to illustrate results and the countries for which they are representative of cost patterns when diagnostic strategies are compared

\section{Eight representative countries Associated 36 countries}

\section{South Africa}

The Russian Federation

China

India

Myanmar

Kenya

Estonia

Kazakhstan
Brazil, Indonesia, Nigeria, Pakistan, the Philippines, Thailand and Vietnam Afghanistan, Bangladesh and Cambodia

Democratic Republic of the Congo, Ethiopia, Mozambique, Uganda, United Republic of Tanzania and Zimbabwe

Lithuania and Latvia

Armenia, Azerbaijan, Bulgaria, Belarus, Georgia, Kyrgyzstan, Republic of Moldova, Tajikistan, Ukraine and Uzbekistan 
TABLE 5 Global estimates of total annual costs in US\$ millions using 2011 prices presented as sensitivity analysis for life expectancy for equipment, for unit cost of cultures and resulting unit cost per person tested ${ }^{\#}$

\begin{tabular}{|c|c|c|c|c|c|}
\hline \multirow{2}{*}{$\begin{array}{l}\text { Variable considered in } \\
\text { sensitivity analysis }\end{array}$} & \multicolumn{2}{|c|}{ Total cost of diagnostic strategy } & \multicolumn{2}{|c|}{ Unit cost per person tested } & \multirow{2}{*}{$\begin{array}{c}\text { Best estimate of } \\
\text { numbers to be tested } \\
\text { globally }\end{array}$} \\
\hline & Xpert MTB/RIF & $\begin{array}{l}\text { Conventional } \\
\text { diagnostics }\end{array}$ & Xpert MTB/RIF & $\begin{array}{l}\text { Conventional } \\
\text { diagnostics }\end{array}$ & \\
\hline
\end{tabular}

\begin{tabular}{|c|c|c|c|c|c|}
\hline \multicolumn{6}{|l|}{$\begin{array}{l}\text { Life expectancy of } \\
\text { GeneXpert machine } \\
5 \text { years (unit cost of } \\
\text { culture US\$17.4) }\end{array}$} \\
\hline TB-SS & $434-468$ & 179 & $16-18$ & 6.7 & 26600000 \\
\hline TB-SS, HIV+ & $90-101$ & 166 & $23-26$ & 43 & 3897376 \\
\hline MDR-TB, high risk & $70-89$ & 123-191 & $38-49$ & $67-104$ & 1828259 \\
\hline \multicolumn{6}{|l|}{$\begin{array}{l}\text { Life expectancy of } \\
\text { GeneXpert machine } \\
10 \text { years }\end{array}$} \\
\hline TB-SS & $407-436$ & 152 & $15-16$ & 5.7 & 26600000 \\
\hline TB-SS, HIV+ & 73-81 & 126 & $19-21$ & 32 & 3897376 \\
\hline MDR-TB, high risk & $54-69$ & $96-156$ & $30-38$ & $53-85$ & 1828259 \\
\hline \multicolumn{6}{|l|}{ Unit cost of culture } \\
\hline \multicolumn{6}{|l|}{ US\$ 12.1} \\
\hline TB-SS & $430-463$ & 177 & $16-17$ & 6.7 & 26600000 \\
\hline TB-SS, HIV+ & 89-101 & 150 & $23-26$ & 38 & 3897376 \\
\hline MDR-TB, high risk & $68-87$ & $114-182$ & $37-48$ & $62-100$ & 1828259 \\
\hline \multicolumn{6}{|l|}{ Unit cost of culture } \\
\hline \multicolumn{6}{|l|}{ US\$ 22.8} \\
\hline TB-SS & $439-473$ & 181 & $17-18$ & 6.8 & 26600000 \\
\hline TB-SS, HIV+ & $90-102$ & 183 & $23-26$ & 47 & 3897376 \\
\hline MDR-TB, high risk & $72-90$ & $132-200$ & $39-49$ & $72-109$ & 1828259 \\
\hline \multicolumn{6}{|l|}{$\begin{array}{c}\text { GeneXpert machines } \\
\text { underused at } 50 \%\end{array}$} \\
\hline TB-SS & $505-559$ & 179 & $19-21$ & 6.7 & 26600000 \\
\hline TB-SS, HIV+ & $101-113$ & 166 & $26-29$ & 43 & 3897376 \\
\hline MDR-TB, high risk & $75-95$ & $123-191$ & $41-52$ & $67-104$ & 1828259 \\
\hline \multicolumn{6}{|l|}{$\begin{array}{c}\text { GeneXpert machines } \\
\text { underused at } 25 \%\end{array}$} \\
\hline TB-SS & $585-638$ & 179 & $22-24$ & 6.7 & 26600000 \\
\hline TB-SS, HIV+ & $113-125$ & 166 & $29-32$ & 43 & 3897376 \\
\hline MDR-TB, high-risk & 80-101 & 123-191 & $44-55$ & $67-104$ & 1828259 \\
\hline
\end{tabular}

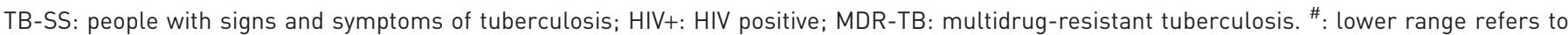
cost estimate with culture and drug susceptibility testing (DST) on solid media; upper range refers to cost estimate with culture and DST on liquid media. ": there is some overlap in the number of tests between the group of HIV+ individuals with TB signs and symptoms and the group of individuals at risk of having MDR-TB. However, it should be noted that this overlap is limited, as most countries with a high prevalence of HIV are in Africa, where the burden of MDR-TB is relatively low.

year would be needed to test for TB. If all individuals presenting at health facilities with signs and symptoms of TB were tested for TB using Xpert MTB/RIF, a best estimate of 26 million tests per year would be needed (table 5).

Worldwide, the total cost per year of using Xpert MTB/RIF (including the conventional diagnostics needed to confirm or rule out a diagnosis of MDR-TB) ranged from US\$ 70-89 million to test only those at highrisk of having MDR-TB, to US\$ 90-101 million for testing all people living with HIV with TB signs and symptoms, to US\$ 434-468 million for testing all people with TB signs and symptoms (figs 1 and 2). The total costs of using conventional diagnostics according to WHO-recommended algorithms in these same population groups were US\$ 123-191 million (the lower and upper ends of the range are costs using solid and liquid media for culture and DST, respectively), US\$166 million and US\$ 179 million, respectively. There are no ranges for the latter two groups because, in the first case, only use of liquid media is recommended and, in the second case, neither culture nor DST are part of the diagnostic algorithm. 


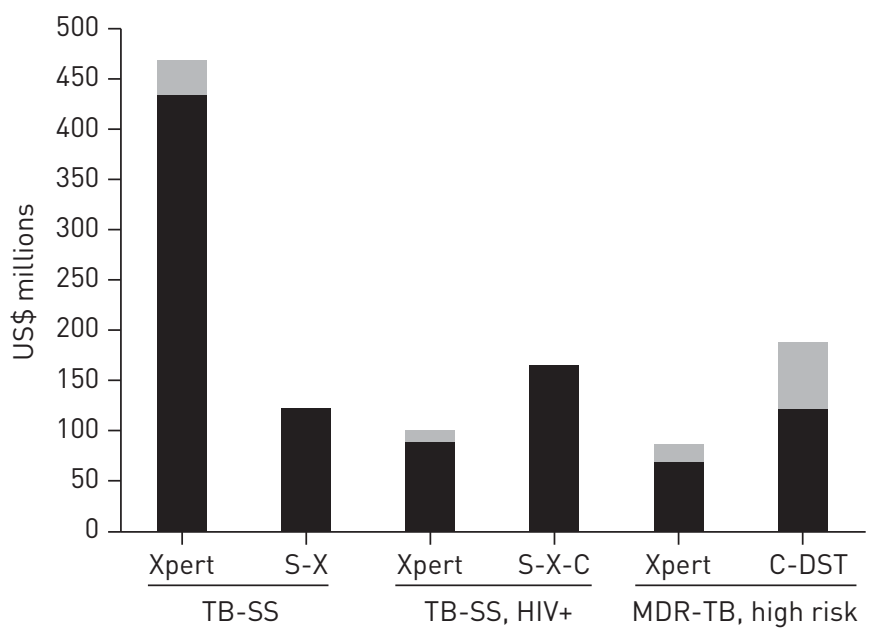

FIGURE 1 Global estimates of the annual cost of tuberculosis (TB) and multidrug-resistant (MDR)-TB diagnosis using Xpert MTB/RIF, compared with the costs of conventional diagnostics following World Health Organization-recommended algorithms in US\$ millions using 2011 prices. Estimates include costs for solid and/or liquid media for culture and drug susceptibility testing (C-DST). The light grey section of the bar depicts the additional cost for liquid media of culture and/or DST. S: smear microscopy; X: radiograph; c: culture; TB-SS: people with signs and symptoms of tuberculosis; HIV+: HIV-positive.

In a strategy using Xpert MTB/RIF, the Xpert MTB/RIF cartridge is the biggest item in the total cost of testing those with TB signs and symptoms, including those living with HIV (fig. 2). For testing among people at risk of MDR-TB, the cost of conventional culture and DST represents about $50 \%$ of the total cost.

\section{Number of test and costs in the 36 high TB and MDR-TB burden countries}

The eight countries shown in figure 3 represent the relative cost patterns found in the other 28 high TB burden or high MDR-TB burden countries. For every country, using Xpert MTB/RIF was a lower cost approach to diagnosis of MDR-TB than using conventional diagnostics (culture and DST) alone, sometimes by a large amount (fig. 3).

In low-income countries with a high prevalence of HIV (as illustrated by Kenya, which represents the pattern in the Democratic Republic of Congo, Ethiopia, Mozambique, Tanzania, Uganda and Zimbabwe), the cost of using Xpert MTB/RIF to diagnose TB in people living with HIV was less than the cost of using conventional diagnostics. In countries with a low prevalence of HIV, using Xpert MTB/RIF to test for TB in people living with HIV with TB signs and symptoms was either less expensive or of similar cost compared with the use of conventional diagnostics according to the WHO-recommended algorithm (as illustrated by India and Myanmar, which represent the pattern seen in, among others, Brazil, Thailand, Indonesia and

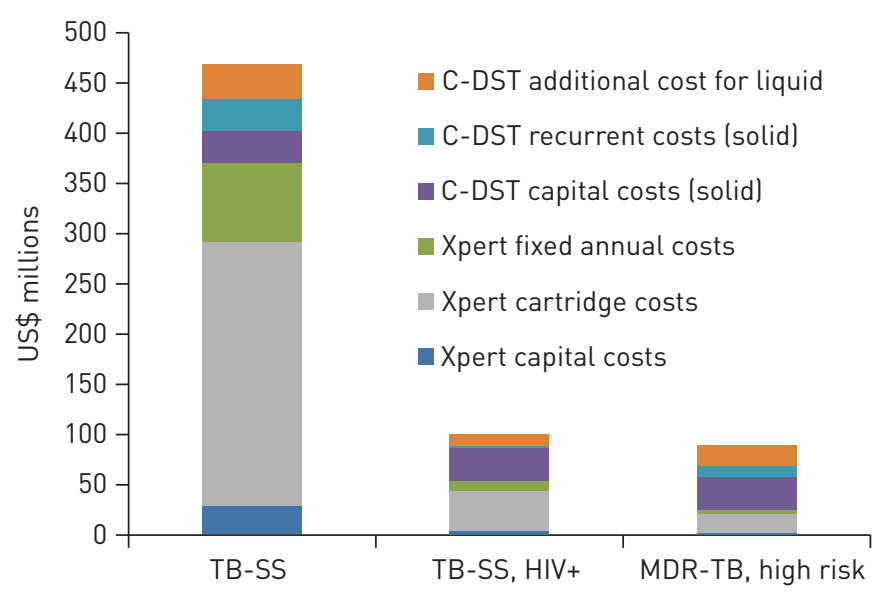

FIGURE 2 Global estimates of the annual cost of tuberculosis (TB) and multidrug-resistant (MDR)-TB diagnosis using Xpert MTB/RIF, breakdown of costs in US\$ millions using 2011 prices. TB-SS: people with signs and symptoms of tuberculosis; HIV+: HIV-positive; C-DST: culture and drug susceptibility testing. 

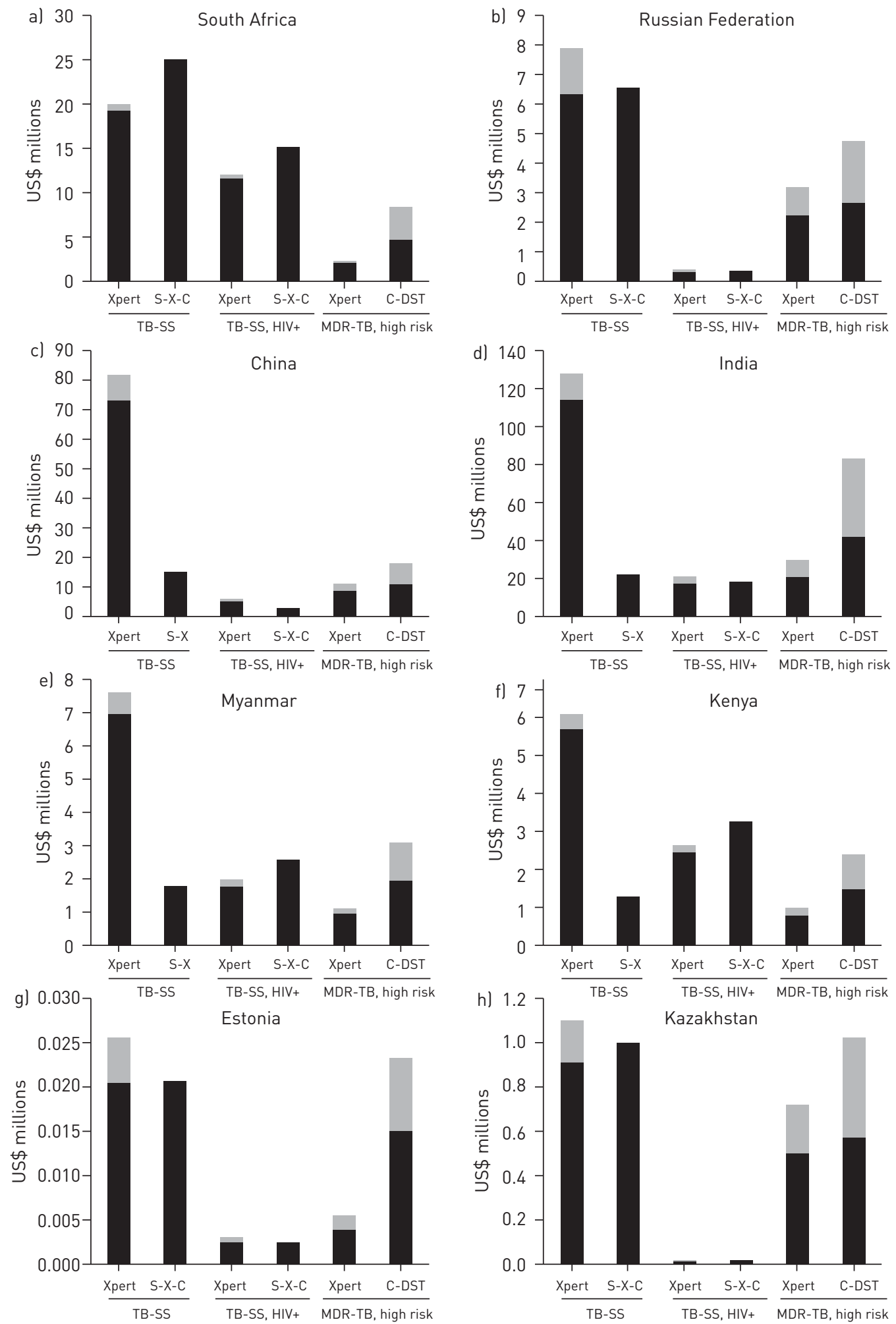

FIGURE 3 Estimated annual cost of tuberculosis (TB) and multidrug-resistant (MDR)-TB diagnosis using Xpert MTB/ RIF, compared with the costs of conventional diagnostics following World Health Organization-recommended algorithms, in the following representative high-burden countries: a) South Africa, b) Russian Federation, c) China, d) India, e) Myanmar, f) Kenya, g) Estonia and h) Kazakhstan. Costs are in US\$ millions using 2011 prices. Estimates include costs for solid and/or liquid media for culture and drug susceptibility testing (C-DST). The light grey section of the bar depicts the additional cost for liquid media of culture and/or DST. TB-SS: people with signs and symptoms of tuberculosis; HIV+: HIV-positive; S: smear microscopy; X: radiograph; c: culture. 
Bangladesh). In almost all countries (33 out of 36), the cost of using Xpert MTB/RIF to test for TB in people living with HIV was similar or lower in cost than the conventional culture-based diagnostic algorithm recommended by WHO.

For almost all countries, using Xpert MTB/RIF to test all people with TB signs and symptoms would increase costs by approximately five-fold compared with the conventional practice of smear microscopy and follow-on chest radiograph for those with smear-negative results. The major exceptions were South Africa and the Russian Federation. In South Africa, the cost of using Xpert MTB/RIF for all people with TB signs and symptoms appeared to be less costly compared with the costs of using conventional diagnostics. For the Russian Federation, annual costs increased by about 20\%. The reason for the different results for these two countries is that tests for $\mathrm{TB}$ and MDR-TB using conventional culture is already a routine part of $\mathrm{TB}$ diagnosis. In Russia, the cost of using Xpert MTB/RIF was higher than conventional diagnostics (as opposed to South Africa) because the proportion of new cases that are likely to have MDR-TB in Russia is ten times higher than in South Africa (18\% compared with 1.8\%) [1], and therefore there is a greater need for followon tests to confirm or rule-out resistance to isoniazid and rifampicin.

\section{Affordability at country level}

The affordability of Xpert MTB/RIF in the 36 high TB and/or high MDR-TB burden countries relative to national funding for TB care and control in 2011 is illustrated in figure 4.

For people suspected of having MDR-TB, the cost of Xpert MTB/RIF represents $<4 \%$ of annual funding for $\mathrm{TB}$ in 24 out of 36 countries, including all of the European countries where the prevalence of MDR-TB among TB cases is highest. In several high TB burden countries in Asia, as well as Nigeria and the Democratic Republic of Congo, the cost ranged from 5\% (both African countries) to $17 \%$ in Pakistan.

For HIV-positive people with TB signs and symptoms, the cost of using Xpert MTB/RIF represents $<4 \%$ of annual funding for TB care and control in 18 out of 36 countries, including all of the European countries, with a range from $0.02 \%$ of national TB funding in Kazakhstan to $20 \%$ in Zimbabwe. In 27 out of 36 countries, the cost of using Xpert MTB/RIF for HIV-positive people with TB signs and symptoms was $<10 \%$ of the available funding for TB care and control in 2011. In eight out of the nine African countries the cost of using Xpert MTB/RIF was only $1-3 \%$ of the approved funding in the PEPFAR operational plans of 2011; in the Democratic Republic of Congo it represents 6\%.

For all people with TB signs and symptoms, the cost of using Xpert MTB/RIF represents $<10 \%$ of annual funding for TB care and control in high burden countries in Europe as well as Brazil and South Africa, with costs negligible as a proportion of total spending on TB care and control in some European countries, including the Russian Federation. In most of the high TB burden countries in Africa and Asia, costs represented at least $20 \%$ of TB spending in 2011, with much higher figures of $>80 \%$ in India, Bangladesh, Indonesia and Pakistan.

\section{Sensitivity analysis}

The results of sensitivity analyses are shown in table 5. If the useful life of equipment is 10 years instead of 5 years and, using the baseline price per cartridge (US\$ 9.98), the total cost of using Xpert MTB/RIF would be lowered by $7-28 \%$, depending on the population group. Changes in the unit cost of culture, within the plausible range reported in the literature, had very small effects on total costs of strategies using Xpert MTB/ RIF $(<1 \%)$ and on testing for MDR-TB using conventional diagnostics only $(<5 \%)$. The effect on total costs of testing using conventional diagnostics for people living with HIV was bigger, at $\pm 10-11 \%$. If purchased GeneXpert instruments are used at only 50\% capacity, the unit cost per person tested would increase by US\$ 3 (up from about US\$ 16-18 in the baseline analysis) and, if used at 25\% capacity, the unit cost per person tested would increase by US\$ 9 .

\section{Discussion}

This is the first study to assess the global costs of rolling-out Xpert MTB/RIF for the rapid diagnosis of TB and drug-resistant TB, as well as the likely cost in all of the 36 high TB and high MDR-TB burden countries. Our results suggest that Xpert MTB/RIF reduces the costs of diagnosing MDR-TB globally and in all 36 countries, and that in 33 out of 36 countries, as well as globally, it reduces the cost of diagnosing TB among people living with HIV, compared with the use of only conventional diagnostics according to WHO guidelines. As a consequence, for these population groups, Xpert MTB/RIF is more affordable than conventional diagnostics. In high MDR-TB countries, the cost of using Xpert MTB/RIF to diagnose MDR$\mathrm{TB}$ represents $<4 \%$ of available TB funding. In most high TB burden African countries, the cost of using Xpert MTB/RIF to diagnose TB in HIV-positive people with TB signs and symptoms represents only $1-3 \%$ of the funding approved for PEPFAR operational plans. In contrast, the cost of using Xpert MTB/RIF to 
a)

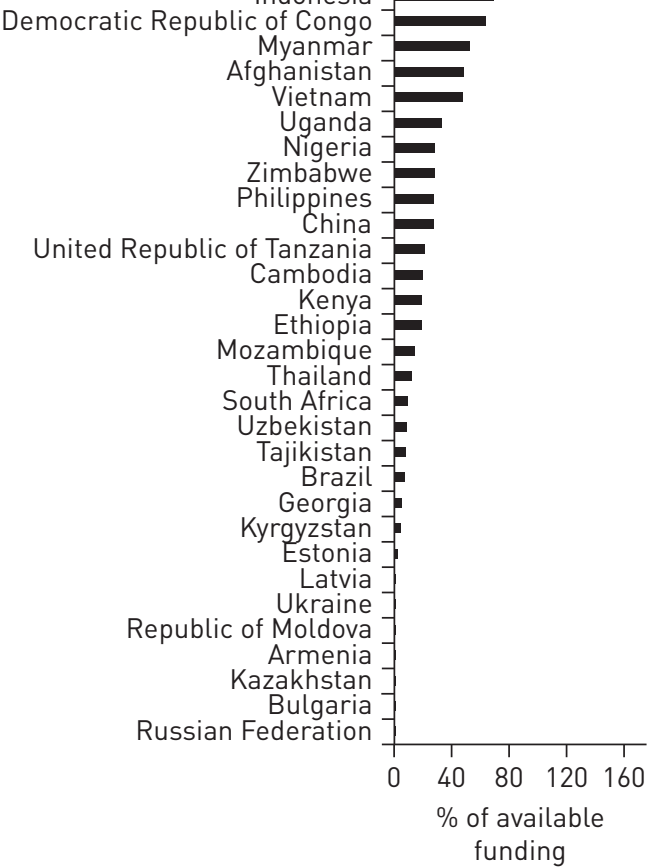

b)

Indonesia

Democratic Republic of Congo Myanmar India Bangladesh Nigeria

United Republic of Tanzania Mozambique Kenya Pakistan Vietnam Afghanistan South Africa Ethiopia

Philippines

Thailand China Cambodia Brazil Uzbekistan

Tajikistan Estonia Ukraine

Kyrgyzstan Latvia Georgia Republic of Moldova Russian Federation Armenia Kazakhstan Bulgaria

051015202530
$\%$ of available
funding

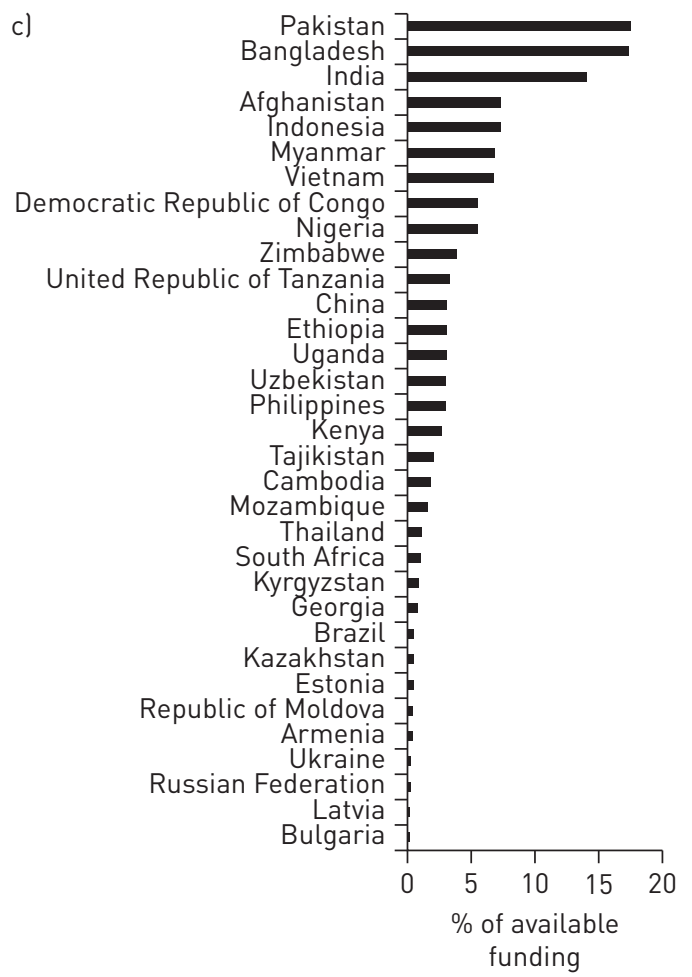

FIGURE 4 Total annual cost of tuberculosis (TB) and multidrug-resistant (MDR)-TB diagnosis using Xpert MTB/RIF as a proportion of available national funding for TB in 2011 in 33 high TB burden and high multidrug-resistant (MDR)-TB burden countries in individuals with a) TB-signs and symptoms (SS), b) TB-SS and HIV-positive and c) high-risk of MDR-TB. Azerbaijan, Belarus and Lithuania are excluded because there were no data available on funding for TB. 
diagnose TB in all people presenting with signs and symptoms of TB disease is about five times higher than conventional diagnostics in most countries, although in several high MDR-TB burden countries in Europe, as well as other middle-income countries, the cost represents a small share of total national spending on TB care and control each year.

Six limitations of our analysis should be noted. 1) We may have underestimated the annual fixed costs of using Xpert MTB/RIF each year, which include staff, training, technical assistance and calibration. We used the best information currently available, which suggests a cost per year and per machine of US\$11 800 [21]. By 2013 there will be much more evidence from data that are being collected by early implementers and our analyses can be updated. 2) For strategies using Xpert MTB/RIF, we included the cost of follow-on DST for two drugs (rifampicin and isoniazid). In settings with high levels of MDR, such confirmation of rifampicin resistance is not essential; if only DST for isoniazid is performed, costs will be lower than our estimates suggest. 3) We were not able to assess the cost implications of the alternative strategies for patients. It will be important to consider how these are affected by the introduction of Xpert MTB/RIF; in theory, Xpert MTB/ RIF should reduce costs to patients by reducing the number of visits to a health facility for diagnostic tests. Studies are now underway in several countries [34]. 4) We used a single unit cost for culture and DST for all countries. While these unit costs were based on amounts reported in the published literature and we incorporated uncertainty in our analyses, in particular to explore the impact of different unit costs of culture tests on total costs, more evidence on the cost of culture and DST in varied country settings would be useful. The methods used in our study could also be replicated or adapted at country level, based on the conventional diagnostic algorithms in use (e.g. with or without radiographs) and available country-specific data on the unit costs of culture, DST and radiographs. 5) The costs of transporting culture and DST specimens were not included; it is thus possible that the cost of conventional diagnostics has been underestimated, since Xpert MTB/RIF is a more decentralised technology that does not require such frequent transportation of specimens. 6) We did not attempt to account for the additional costs associated with Xpert MTB/RIF cartridges that are lost as a consequence of factors such as high temperatures, failure to use cartridges before their expiry date or power outages; this will become possible once more evidence on the frequency of these problems becomes available, probably in 2013, from early implementers of the technology.

Our analyses suggest that high MDR-TB burden countries implementing Xpert MTB/RIF should first focus on using the test to diagnose drug-resistant TB, while countries with a high prevalence of HIV but low levels of MDR should focus on using it to diagnose TB in people living with HIV. This is fully in line with WHO policy guidance issued in 2011. From a cost and affordability perspective, countries that already use culture as a routine part of TB diagnosis could also start to shift to the use of Xpert MTB/RIF for all people with TB signs and symptoms. Its introduction to test all people with TB signs and symptoms is also affordable in middle-income countries, but to be financially viable in low-income countries a big increase in funding for TB control and/or further reductions in the price of the Xpert MTB/RIF assay is/are required. As stated at the beginning of our methods sections, our analysis focuses on the cost of alternative ways of diagnosing TB and drug-resistant TB. If Xpert MTB/RIF is used to test for TB among people living with HIV or all people with TB signs and symptoms, the simultaneous testing for TB and rifampicin-resistant TB will identify larger numbers of patients with drug-resistant TB compared with the conventional algorithm that will identify only TB. When introducing Xpert MTB/RIF among these population groups, it is therefore essential that countries assess, plan and mobilise funds for the probable number of people that will be identified as having MDR-TB, for whom a longer and most costly second-line drug regimen is the appropriate course of treatment. Most of the funding required for treatment of MDR-TB is needed in upper and lower middle-income countries [14], notably China, India, South Africa and 13 out of 15 of the high MDR-TB burden European countries (the exceptions are Tajikistan and Kyrgyzstan, which are lowincome), where domestic capacity to fund such treatment is relatively good [1]. In these countries, the lower costs of Xpert MTB/RIF combined with rapid results and much reduced need for sophisticated laboratory capacity to identify resistance to isoniazid and rifampicin (conventional DST is required only for those with a rifampicin-resistant result rather than all those suspected of having MDR-TB) also mean that using Xpert MTB/RIF could make a big contribution to facilitating the scale-up of diagnosis and treatment of MDR-TB in line with global planning targets.

Monitoring treatment of TB and MDR-TB requires that the laboratory capacity for microscopy and culture is retained or extended where needed. Published evidence on the cost-effectiveness of MDR-TB treatment shows that the monitoring costs are only between $3 \%$ and $6 \%$ of the total cost of treatment per MDR-TB patient; these costs typically include expansion of laboratory capacity, culture tests and tests for drug susceptibility $[25,27,28,35]$. Therefore, the cost implications of an increase in the volume of people diagnosed with MDR-TB when Xpert MTB/RIF is implemented will be relatively minor from the laboratory monitoring perspective. 


\section{Conclusions}

Scaling-up capacity to diagnose TB and MDR-TB will greatly facilitate TB prevention, care and control. From a cost and affordability perspective, wide-scale introduction of Xpert MTB/RIF to diagnose MDR-TB and to diagnose TB in people living with HIV is warranted, in line with WHO policy guidance. Its introduction to test all people with TB signs and symptoms is affordable in middle-income countries, but to be financially viable in low-income countries a big increase in funding for TB control and/or further reductions in the price of the Xpert MTB/RIF assay is/are required.

\section{References}

1 World Health Organization. Global tuberculosis control: WHO report 2011. Geneva, WHO Press, 2011. http:// whqlibdoc.who.int/publications/2011/9789241564380_eng.pdf Date last accessed: July 2, 2013.

2 Getahun H, Harrington M, O'Brien R, et al. Diagnosis of smear-negative pulmonary tuberculosis in people with HIV infection or AIDS in resource-constrained settings: informing urgent policy changes. Lancet 2007; 369: 2042-2049.

3 Small PM, Pai M. Tuberculosis diagnosis-time for a game change. N Engl J Med 2010; 363: 1070-1071.

4 World Health Organization. Improving the diagnosis and treatment of smear-negative pulmonary and extrapulmonary tuberculosis among adults and adolescents. Recommendations for HIV-prevalent and resourceconstrained settings. Geneva, WHO Press, 2007. http://whqlibdoc.who.int/hq/2007/WHO_HTM_TB_2007. 379_eng.pdf Date last accessed: July 2, 2013.

5 World Health Organization. Multidrug and extensively drug-resistant TB (M/XDR-TB): 2010 global report on surveillance and response. Geneva, WHO Press, 2010. http://whqlibdoc.who.int/publications/2010/ 9789241599191_eng.pdf Date last accessed: July 2, 2013.

6 Steingart KR, Henry M, Ng V, et al. Fluorescence versus conventional sputum smear microscopy for tuberculosis: a systematic review. Lancet Infect Dis 2006; 6: 570-581.

7 Boehme CC, Nicol MP, Nabeta P, et al. Feasibility, diagnostic accuracy, and effectiveness of decentralised use of the Xpert MTB/RIF test for diagnosis of tuberculosis and multidrug resistance: a multicentre implementation study. Lancet 2011; 377: 1495-1505.

8 Helb D, Jones M, Story E, et al. Rapid detection of Mycobacterium tuberculosis and rifampin resistance by use of ondemand, near-patient technology. J Clin Microbiol 2010; 48: 229-237.

9 Van Rie A, Page-Shipp L, Scott L, et al. Xpert ${ }^{2}$ MTB/RIF for point-of-care diagnosis of TB in high-HIV burden, resource-limited countries: hype or hope? Expert Rev Mol Diagn 2010; 10: 937-946.

10 Boehme CC, Nabeta P, Hillemann D, et al. Rapid molecular detection of tuberculosis and rifampin resistance. N Engl J Med 2010; 363: 1005-1015.

11 World Health Organization. Policy statement: automated real-time nucleic acid amplification technology for rapid and simultaneous detection of tuberculosis and rifampicin resistance: Xpert MTB/RIF system. Geneva, WHO Press, 2011. http://who.int/tb/laboratory/mtbrifrollout/en/index.html Date last accessed: July 2, 2013.

12 World Health Organization. Guidelines for the programmatic management of drug-resistant tuberculosis - 2011 update. Geneva, WHO Press, 2011. http://whqlibdoc.who.int/publications/2011/9789241501583_eng.pdf Date last accessed: July 2, 2013.

13 World Health Organization. Implementation and roll-out of Xpert MTB/RIF - Update May 2012. Geneva, WHO Press, 2012. www.stoptb.org/wg/gli/assets/documents/Xpert\%20MTB-RIF\%20UPDATE\%20May\%202012.pdf Date last accessed: April 18, 2013.

14 World Health Organization and Stop TB Partnership. The global plan to stop TB 2011-2015: transforming the fight towards elimination of tuberculosis. Geneva, WHO Press, 2010. http://whqlibdoc.who.int/publications/2010/ 9789241500340_eng.pdf Date last accessed: July 2, 2013.

15 Trébucq A, Enarson DA, Chiang CY, et al. Xpert MTB/RIF for national tuberculosis programmes in low-income countries: when, where and how? Int J Tuberc Lung Dis 2011; 15: 1567-1572.

16 Singh JA, Bhan A. The ethics of national tuberculosis programmes in low-income countries not rolling out Xpert MTB/RIF. Int J Tuberc Lung Dis 2011; 15: 1563.

17 Vassall A, van Kampen S, Sohn H, et al. Rapid diagnosis of tuberculosis with the Xpert MTB/RIF assay in high burden countries: a cost-effectiveness analysis. PLoS Med 2011; 8: e1001120.

18 Meyer-Rath G., Bistline K., Long L., et al. The incremental cost of introducing Xpert® MTB/RIF into the South African national tuberculosis programme: results of the national TB cost model 2011/12-2016/17. HE ${ }^{2}$ RO Policy Brief Number 1. Johannesburg, Health Economics and Epidemiology Research Office, 2011.

19 Theron G, Pooran A, Peter J, et al. Do adjunct TB tests, when combined with Xpert MTB/RIF, improve accuracy and the cost of diagnosis in a resource-poor setting? Eur Respir J 2012; 40: 161-168.

20 World Health Organization. Towards universal access to diagnosis and treatment of multidrug-resistant ans extensively drug-resistant tuberculosis by 2015: WHO Progress Report 2011. Geneva, WHO Press, 2011. http:// www.who.int/tb/publications/2011/mdr_report_2011/en/ Date last accessed: July 2, 2013.

21 World Health Organization. Rapid implementation of the Xpert MTB/RIF diagnostic test: technical and operational "How-to"; practical considerations. Geneva, WHO Press, 2011. http://whqlibdoc.who.int/publications/ 2011/9789241501569_eng.pdf Date last accessed: July 2, 2013.

22 World Health Organization. Treatment of Tuberculosis Guidelines, 4th Edn. Geneva, WHO Press, 2010. http:// whqlibdoc.who.int/publications/2010/9789241547833_eng.pdf Date last accessed: April 17, 2013.

23 Zignol M, van Gemert W, Falzon D, et al. Surveillance of anti-tuberculosis drug resistance in the world: an updated analysis, 2007-2010. Bull World Health Organ 2012; 90: 111-119d.

24 World Health Organization. TB planning and budgeting tool. Geneva, World Health Organization. www.who.int/ tb/dots/planning_budgeting_tool/en/index.html Date last accessed: February 15, 2012.

25 Tupasi TE, Gupta R, Quelapio MI, et al. Feasibility and cost-effectiveness of treating multidrug-resistant tuberculosis: a cohort study in the Philippines. PLoS Med 2006; 3: e352. 
Mueller DH, Mwenge L, Muyoyeta M, et al. Costs and cost-effectiveness of tuberculosis cultures using solid and liquid media in a developing country. Int J Tuberc Lung Dis 2008; 12: 1196-1202.

27 Suárez PG, Floyd K, Portocarrero J, et al. Feasibility and cost-effectiveness of standardised second-line drug treatment for chronic tuberculosis patients: a national cohort study in Peru. Lancet 2002; 359: 1980-1989.

28 Floyd K, Hutubessy R, Kliiman K, et al. Cost and cost-effectiveness of MDR-TB treatment in Estonia and Russia. Eur Respir J 2012; 40: 133-142.

29 UNITAID. UNITAID approves US\$ 30 million for innovative project to roll out ground-breaking tuberculosis test at reduced cost. www.unitaid.eu/en/resources/press-centre/news/986-public-private-partnership-announces-immediate40-percent-cost-reduction-for-rapid-tb-test Date last accessed: July 3, 2013.

30 Foundation for Innovative New Diagnostics. FIND-negotiated prices for BACTEC and MGIT and country list. www.finddiagnostics.org/about/what_we_do/successes/find-negotiated-prices/bactec-mgit.html Date last accessed: April 17, 2013.

31 Drummond MF, Sculpher MJ, Torrance GW, et. al. Methods for the Economic Evaluation of Health Care Programmes, 3rd Edn. Oxford, Oxford University Press, 2005.

32 World Health Organization. Tuberculosis country profiles. www.who.int/tb/country/data/profiles/en/index.html Date last accessed: April 17, 2013.

33 The U.S. president'semergency plan for AIDS relief (PEPFAR). Fiscal Year 2011: PEPFAR Operational Plan. www. pepfar.gov/documents/organization/183974.pdf Date last accessed: April 17, 2013.

34 TREAT TB. Xpert® MTB/RIF Research Projects, 2012. http://xrmt.treattb.org/projects-listing2 Date last accessed: April 17, 2013.

35 Fitzpatrick C, Floyd K. A systematic review of the cost and cost effectiveness of treatment for multidrug-resistant tuberculosis. Pharmacoeconomics 2012; 30: 62-80. 